\title{
Understanding autism in the light of sex/gender
}

\author{
Meng-Chuan Lai ${ }^{1,2,3^{*}}$, Simon Baron-Cohen ${ }^{1,2}$ and Joseph D Buxbaum ${ }^{4}$
}

\section{Editorial}

Autism has long been described as a predominantly male condition, with a widely cited male:female ratio of 4 to $5: 1$ [1]. Over the past two decades, we have witnessed a trend towards a decreasing male-predominance [2]. Latest largescale population/community-based epidemiological studies converge to show a ratio of 2 to 3:1 [3]. The implications of this are important.

Females with autism may have been underidentified and therefore underrepresented in the past, and consequently, the previous scientific and clinical literature likely may have provided a male-biased understanding of autism. However, a relative male-predominance remains a stable observation over time, which has led to fruitful aetiological and developmental investigations and theories $[4-7,3]$. For the field to move towards an integrated understanding of the whole autism spectrum, it is important that females are not overlooked, and their particular experiences are properly documented [8]. Sex and gender provide unique angles for understanding causal mechanisms in atypical human developmental conditions [9] and should be a central theme in the understanding to autism and its vast heterogeneity $[3,10]$.

Note that the term 'sex' refers to 'the biological and physiological characteristics that define men and women', and 'gender' refers to 'the socially constructed roles, behaviors, activities, and attributes that a given society considers appropriate for men and women' [11]. Since many human studies of autism focus on children, adolescents and adults, it is often difficult to empirically separate the effect of sex and gender, since gendered socialization begins at birth. Therefore, unless when we specifically refer to 'sex' or 'gender' separately, as defined here, we use the term 'sex/gender' to note the inevitable overlap between them [12].

Molecular Autism, since its launch in 2010, has published a range of research in relation to sex/gender and

\footnotetext{
* Correspondence: mc145@cam.ac.uk

'Autism Research Centre, Department of Psychiatry, University of Cambridge, Douglas House, 18B, Trumpington Road, Cambridge CB2 8AH, UK

${ }^{2}$ CLASS Clinic, Cambridgeshire and Peterborough NHS Foundation Trust,

Chitra Sethia Autism Centre, The Gatehouse, Fulbourn Hospital, Fulbourn, Cambridge CB21 5EF, UK

Full list of author information is available at the end of the article
}

autism, for example, about male-female differences and female-specific characteristics of autism [13-15]; issues related to potentially 'missed' females on the spectrum, diagnostic overshadowing and co-occurrence [16-19]; sex/gender-differential traits in the general population in relation to the liability of developing autism [20,21]; and biological aetiologies associated with sex-differential liability [22-28].

Acknowledging the need to bring sex and gender to centre stage of autism research, in 2014, we launched a call-for-papers for the inaugural thematic series of this journal, 'Understanding the links between sex/gender and autism.' This thematic series are comprised of two batches of research articles, with the first being published in May 2015 [29-33], followed by a second later in 2015.

It has recently been proposed that research into sex/ gender and autism could benefit from adapting a conceptual framework including four separate but interlinked themes: (1) nosological and diagnostic challenges, (2) sex/gender-independent and sex/gender-dependent characteristics, (3) general models of aetiology regarding liability and threshold, and (4) specific aetiologicaldevelopmental mechanisms [3]. The five articles in this issue cover all of these four major themes, providing novel and important findings.

Addressing aspects of the first theme and building on recent investigations into the co-occurrence of increased autistic traits [16-18] and autism diagnoses [34] in individuals with eating disorders, Mandy and Tchanturia's case series [33] report that in ten women with eating disorders and social/flexibility difficulties, seven were judged to have an autism spectrum disorder (ASD) by gold-standard diagnostic procedures (particularly including in-person observation using the Autism Diagnostic Observation Schedule). Although all seven women with ASD presented difficulties closely related to autism early in life and prior to their eating disorder diagnoses, only one had received an ASD diagnosis in childhood. Findings from a referred case series may not always reflect what is happening in community or family clinics or general mental health services; however, Mandy and 
Tchanturia raise the alarm in relation to potential under-/ misdiagnosis of autism or diagnostic 'overshadowing' in females with autism with an eating disorder. They do this by employing formal diagnostic procedures, rather than merely measuring self-reported dispositional traits.

A similar point is made through case series of other kinds of psychopathology [35-37]. Females with autism tend to be identified later than males [38-40], and diagnoses tend to be given when autistic characteristics or concurrent behavioural/cognitive difficulties are more severe [41,42]. Although women (as well as men) diagnosed with autism have been shown to have high rates of concurrent psychiatric diagnoses [43,44], it is unknown whether females are more likely than males to first get other psychiatric diagnoses (either truly comorbid or misidentified) before the identification of their autism. How diagnostic overshadowing, substitution or co-occurrence influences the timing and likelihood of the identification of autism in females (and the associated need for support) should be an important focus for future epidemiological, clinical and health-care research [3].

Identifying similarities and differences between males and females with autism across levels has the potential to inform both identification (for example, behavioural features) and understanding of aetiologies (for example, biological features). Recent investigations have considered aspects of cognition and biology and suggest that, contrary to the conventional view that diagnosed females tend to be 'more severe', they may rather have 'different' biological characteristics compared to males with autism (beyond preexisting normative sex/gender differences); see [45,3] for reviews. Nordahl et al. [32] extend this by showing that there are sex/gender differences in the pattern of altered corpus callosum neuroanatomy in a longitudinal sample of preschooler with autism. They found males and females with autism, compared to same-sex/ gender controls, differ in different callosal subregion volume (classified based on cortical projection zone) and microstructural properties. Interestingly, no sex/gender differences in growth trajectory were discovered, suggesting that the observed sex/gender-dependent white matter characteristics were established prior to age of three or that the age window of this study (3 to 5 yearolds) reflected a period without evident sex/genderdifferential growth patterns. Together with other recent findings on very early sex/gender differences in brain and physical growth [46-48], this suggests male-female biological differences are evident early in life in autism, possibly reflecting the key role of early biological factors giving rise to sex-differential aetiological mechanisms, such as prenatal steroids [49] and associated regulatory mechanisms [29] or early neuroinflammatory mechanisms [50].
Two articles further examine aetiological implications, focusing on the 'female-protective effect' (FPE) hypothesis. Werling and Geschwind [30] use a large sample of multiplex families and twin pairs in the Autism Genetics Resource Exchange (AGRE) cohort to test two predictions from the FPE hypothesis: first, that males show higher rates of autism than females (prediction 1), and second, that risk of autism is greater for the siblings and co-twins of females with autism than siblings and cotwins of males with autism (prediction 2). Prediction 1 has been repeatedly confirmed across studies (that is, the relative male-predominance in prevalence/incidence). Prediction 2 has been supported from general population twin samples by measuring autistic traits [51], yet when examining clinical autism diagnoses, the results are inconsistent and are even negative in some large-scale general population studies [52,53]. Here, Werling and Geschwind show that in multiplex families both predictions are confirmed, using a less biased yet more conservative approach than previous studies (that is, using two probands instead of one to define 'maleonly' (MO) versus 'female-containing' (FC) families, preventing artifactual inflation of recurrence rates in FC families and deflation in MO families).

The contrast between this confirmation of prediction 2 and previous negative general population findings might be due to differences in ascertainment or sensitivity to diagnosis, particularly in females (for example, better sensitivity to detecting autism in females in multiplex families than in general community clinical settings). A further interesting observation is that prediction 1 reflecting FPE (male $>$ female relative risk, $R R=2.25$ ) is more evident and substantial than prediction 2 (sibling in $\mathrm{FC}>$ sibling in $\mathrm{MO}$ families, $\mathrm{RR}=1.46$ ). Although both predictions are thought to reflect FPE, mechanisms leading to prediction 2 may be more complicated. For example, the reason why females are generally less likely to have autism (prediction 1) may be the operation of ubiquitous genetic and/or environmental protective mechanisms to females rather than males. However, reasons causing increased $R R$ in siblings in FC than siblings in MO families (prediction 2) may be contributed further by other risk mechanisms (for example, increased inherited mutations occurring in previous generations and 'carried' by unaffected/undiagnosed females in the family [54]) that act against the ubiquitous female-protective mechanisms. For prediction 2 to be observed, ubiquitous female-protective effects have to be overwhelmed by additional risk mechanisms. Elucidating the different mechanisms/factors contributing to FPE should be a focus of aetiological investigation.

Gockley et al. [31] performed a female-only genomewide association study (GWAS) on the AGRE cohort 
(with replication using the Simons Simplex Collection (SSC) data). Based on the observation of a bimodal distribution of autistic traits in AGRE female but not male participants, they hypothesised that FPE could be mediated by a single, common genetic locus on chromosome $\mathrm{X}$, an obvious candidate for protection to females (that is, aspects of FPE reflected by prediction 1). They concluded that despite the analysis was well powered, no evidence of a common variant accounting for a single FPE locus was observed; however, the possibility of multiple genetic loci contributing to FPE is not excluded. It might be informative to interpret the findings in the light of the different aspects of FPE mentioned above. Genetic markers revealed by a female-only GWAS comparing females with and without autism may be more associated with risk mechanisms that act against and overwhelm ubiquitous female-protective mechanisms, as the comparison is between those being successfully protected (unaffected females) and those affected despite being equally protected (females with autism). In other words, what Gockley et al. showed is probably beyond the associative factors for prediction 1 but more about prediction 2 (that is, risk mechanisms acting against protection). As the authors pointed out in their discussion, mechanisms for FPE are likely to be multi-factorial and may involve both genetic and environmental factors.

There are some other interesting findings revealed by these two aetiological investigations. Contrary to the conventional impression of greater male skew amongst more cognitively able individuals, Werling and Geschwind found in their AGRE sample the male-female ratio is actually smaller at the 'higher-functioning' end, echoing similar recent epidemiological findings [55,56]. These altogether challenge the long-held view that diagnosed females tend to be more 'severely affected' than males (that has been used to formulate and test the multifactorial liability models of autism aetiology [5,57]) and point to the need to reevaluating the liability models and FPE considering sex/gender-dependent mechanisms [3]. Gockley et al., in interpreting their findings, discussed potential environmental factors contributing to FPE; Werling and Geschwind also suggested possibly greater environmental aetiological contribution in males in interpreting the male-specific association between shorter inter-birth intervals and increased autism recurrent risk. Nongenetic (likely including environment and geneenvironment interplay) contributions to the emergence of autism have been highlighted recently [58,53,59-61]. It would be informative to further consider how sex/gender moderates gene-environment mechanisms of autism, such as through sex-specific multiple 'hits' [7].

Most of the aetiological investigations start from phenotypic observations. Sex/gender-related nosological and identification challenges however still receive insufficient examination, potentially biasing aetiological inferences [3]. For example, the bimodal distribution of SRS scores in AGRE females might partially stem from ascertainment characteristics, as Gockley et al. discussed, but it could also partially stem from 'polarised' rating for females by informants, influenced by existing gender stereotypes (that is, rating affected females as more severe because the characteristics are perceived as more deviant from the general population 'female norm' and stereotype whereas rating unaffected females as having even fewer autistic characteristics because they are perceived by the informants as better fitting the typical female norm and stereotype, given the contrast by the presence of affected probands in the family). More discussion into this challenge will be beneficial for advancing our understanding to how sex/gender interacts with aetiological mechanisms in autism.

Finally, Hu et al. [29] look into specific sex-implicated aetiological mechanisms. Their previous studies show that autism may be associated with deficiency in the expression of the retinoic acid-related orphan receptor alpha (RORA) gene, and therefore, dysregulated feedback loops with androgen and oestrogen, as well as the many autism-associated genes regulated by RORA $[62,23,22]$. In their new article, $\mathrm{Hu}$ et al. show that there are sex differences in RORA expression in specific brain regions in both human and mice and in the correlation between RORA and its transcriptional targets. This suggests that, at least in a subgroup of autism, males and females may be differentially affected by dysregulated RORA expression. Specifically in their mice model, disruption of RORA seems to have a more substantial effect in males than females. Although this preliminary study awaits further replication in larger samples, it shows that some aetiological mechanisms of autism could be sex-dependent and involve recursive, multilevel pathways.

More importantly, this has to be delineated in the context of gene-environment interplay. For example, the potential aetiological role of RORA deficiency and prenatal hormonal effects could be an example of geneenvironment correlation in which biological sex plays a moderating role. Recent epidemiologically based endocrine findings show increased prenatal steroidogenic activity being an early 'environmental' risk for later autism diagnosis in males [49]. This could be further dissected in the context of gene-environment interplay. Malespecific risks by environmental factors and geneenvironment interplay as suggested by both $\mathrm{Hu}$ et al. and Werling and Geschwind, and more generally by the well-known findings of increased susceptibility to hazard in males than females during foetal periods, should be a focus of aetiological investigation for autism. 
Autism should not be perceived as a 'male condition'. Females should no longer be underrepresented in future autism research. Unanswered questions span issues from definition, identification, presentation and characteristics to aetiological and developmental mechanisms, and these will be better understood in the light of sex and gender.

We are grateful to all the authors contributing to part 1 of this thematic series, who join forces to elucidate the complex but informative relationships surrounding sex/gender and autism. We hope this will stimulate more research into this topic.

\begin{abstract}
Author details
'Autism Research Centre, Department of Psychiatry, University of Cambridge, Douglas House, 18B, Trumpington Road, Cambridge CB2 8AH, UK. ${ }^{2}$ CLASS Clinic, Cambridgeshire and Peterborough NHS Foundation Trust, Chitra Sethia Autism Centre, The Gatehouse, Fulbourn Hospital, Fulbourn, Cambridge CB21 5EF, UK. ${ }^{3}$ Department of Psychiatry, National Taiwan University Hospital and College of Medicine, No.1 Jen-Ai Road Section 1, Taipei 10051, Taiwan. ${ }^{4}$ Seaver Autism Center for Research and Treatment, Departments of Psychiatry, Neuroscience, and Genetics and Genomic Sciences, Friedman Brain Institute and Mindich Child Health and Development Institute, Icahn School of Medicine at Mount Sinai, 1468 Madison Avenue, New York, NY 10029, USA.
\end{abstract}

Received: 20 April 2015 Accepted: 20 April 2015

Published online: 13 May 2015

\section{References}

1. Fombonne E, Quirke S, Hagen A. Epidemiology of pervasive developmental disorders. In: Amaral DG, Dawson G, Geschwind DH, editors. Autism spectrum disorders. New York, NY: Oxford University Press; 2011. p. 90-111.

2. Jensen CM, Steinhausen HC, Lauritsen MB. Time trends over 16 years in incidence-rates of autism spectrum disorders across the lifespan based on nationwide Danish register data. J Autism Dev Disord. 2014;44(8):1808-18. doi:10.1007/s10803-014-2053-6.

3. Lai MC, Lombardo MV, Auyeung B, Chakrabarti B, Baron-Cohen S. Sex/gender differences and autism: setting the scene for future research. J Am Acad Child Adolesc Psychiatry. 2015;54(1):11-24. doi:10.1016/j.jaac.2014.10.003.

4. Werling DM, Geschwind DH. Understanding sex bias in autism spectrum disorder. Proc Natl Acad Sci U S A. 2013;110(13):4868-9. doi:10.1073/ pnas. 1301602110.

5. Werling DM, Geschwind DH. Sex differences in autism spectrum disorders. Curr Opin Neurol. 2013;26(2):146-53. doi:10.1097/ WCO.0b013e32835ee548.

6. Baron-Cohen S, Lombardo MV, Auyeung B, Ashwin E, Chakrabarti B, Knickmeyer R. Why are autism spectrum conditions more prevalent in males? PLoS Biol. 2011;9(6):e1001081. doi:10.1371/journal.pbio.1001081 PBIOLOGY-D-11-01164.

7. Schaafsma SM, Pfaff DW. Etiologies underlying sex differences in autism spectrum disorders. Front Neuroendocrinol. 2014;35(3):255-71. doi:10.1016/ j.yfrne.2014.03.006.

8. Shefcyk A. Count us in: addressing gender disparities in autism research. Autism. 2015;19(2):131-2

9. Rutter M, Caspi A, Moffitt TE. Using sex differences in psychopathology to study causal mechanisms: unifying issues and research strategies. J Child Psychol Psychiatry. 2003;44(8):1092-115.

10. Lai MC, Lombardo MV, Chakrabarti B, Baron-Cohen S. Subgrouping the autism 'spectrum': reflections on DSM-5. PLoS Biol. 2013;11(4):e1001544. doi:10.1371/journal.pbio.1001544.

11. World Health Organization. What do we mean by 'sex' and 'gender'? World Health Organization. http://www.who.int/gender/whatisgender/en/. 2015.

12. Springer KW, Mager Stellman J, Jordan-Young RM. Beyond a catalogue of differences: a theoretical frame and good practice guidelines for researching sex/gender in human health. Soc Sci Med. 2012;74(11):1817-24. doi:10.1016/ j.socscimed.2011.05.033.
13. Head AM, McGillivray JA, Stokes MA. Gender differences in emotionality and sociability in children with autism spectrum disorders. Mol Autism. 2014;5(1):19. doi:10.1186/2040-2392-5-19.

14. Pohl A, Cassidy S, Auyeung B, Baron-Cohen S. Uncovering steroidopathy in women with autism: a latent class analysis. Mol Autism. 2014;5(1):27. doi:10.1186/2040-2392-5-27

15. Steeb H, Ramsey JM, Guest PC, Stocki P, Cooper JD, Rahmoune H, et al. Serum proteomic analysis identifies sex-specific differences in lipid metabolism and inflammation profiles in adults diagnosed with Asperger syndrome. Mol Autism. 2014;5(1):4. doi:10.1186/2040-2392-5-4.

16. Baron-Cohen S, Jaffa T, Davies S, Auyeung B, Allison C, Wheelwright S. Do girls with anorexia nervosa have elevated autistic traits? Mol Autism. 2013;4(1):24. doi:10.1186/2040-2392-4-24.

17. Rhind C, Bonfioli E, Hibbs R, Goddard E, Macdonald P, Gowers S, et al. An examination of autism spectrum traits in adolescents with anorexia nervosa and their parents. Mol Autism. 2014;5(1):56 doi:10.1186/2040-2392-5-56.

18. Tchanturia K, Smith E, Weineck F, Fidanboylu E, Kern N, Treasure J, et al. Exploring autistic traits in anorexia: a clinical study. Mol Autism. 2013;4(1):44. doi:10.1186/2040-2392-4-44.

19. Nielsen S, Anckarsäter H, Gillberg C, Gillberg C, Råstam M, Wentz E. Effects of autism spectrum disorders on outcome in teenage-onset anorexia nervosa evaluated by the Morgan-Russell outcome assessment schedule: a controlled community-based study. Mol Autism. 2015;6(1):14. doi:10.1186/s13229-015-0013-4

20. Matsuyoshi D, Kuraguchi K, Tanaka Y, Uchida S, Ashida H, Watanabe K. Individual differences in autistic traits predict the perception of direct gaze for males, but not for females. Mol Autism. 2014;5(1):12 doi:10.1186/2040-2392-5-12.

21. Ruzich E, Allison C, Smith P, Watson P, Auyeung B, Ring H, et al. Measuring autistic traits in the general population: a systematic review of the Autism-Spectrum Quotient (AQ) in a nonclinical population sample of 6,900 typical adult males and females. Mol Autism. 2015;6:2. doi:10.1186/2040-2392-6-2.

22. Sarachana T, Hu VW. Genome-wide identification of transcriptional targets of RORA reveals direct regulation of multiple genes associated with autism spectrum disorder. Mol Autism. 2013;4(1):14. doi:10.1186/20402392-4-14.

23. Sarachana T, Hu VW. Differential recruitment of coregulators to the RORA promoter adds another layer of complexity to gene (dys) regulation by sex hormones in autism. Mol Autism. 2013;4(1):39. doi:10.1186/2040-2392-4-39.

24. Ziats MN, Rennert OM. Sex-biased gene expression in the developing brain: implications for autism spectrum disorders. Mol Autism. 2013;4(1):10. doi:10.1186/2040-2392-4-10.

25. Werling DM, Lowe JK, Luo R, Cantor RM, Geschwind DH. Replication of linkage at chromosome 20p13 and identification of suggestive sex-differential risk loci for autism spectrum disorder. Mol Autism. 2014;5(1):13. doi:10.1186/2040-2392-5-13

26. Carayol J, Schellenberg GD, Dombroski B, Genin E, Rousseau F, Dawson G. Autism risk assessment in siblings of affected children using sex-specific genetic scores. Mol Autism. 2011;2(1):17. doi:10.1186/2040-2392-2-17.

27. Auyeung B, Taylor K, Hackett G, Baron-Cohen S. Foetal testosterone and autistic traits in 18 to 24-month-old children. Mol Autism. 2010;1(1):11. doi:10.1186/2040-2392-1-11

28. Crider A, Thakkar R, Ahmed AO, Pillai A. Dysregulation of estrogen receptor beta (ERbeta), aromatase (CYP19A1), and ER co-activators in the middle frontal gyrus of autism spectrum disorder subjects. Mol Autism. 2014;5(1):46. doi:10.1186/2040-2392-5-46.

29. Hu WW, Sarachana T, Sherrard RM, Kocher KM. Investigation of sex differences in the expression of RORA and its transcriptional targets in the brain as a potential contributor to the sex bias in autism. Mol Autism. 2015. doi:10.1186/2040-2392-6-7.

30. Werling DM, Geschwind DH. Recurrence rates provide evidence for sex-differential, familial genetic liability for autism spectrum disorders in multiplex families and twins. Mol Autism. 2015. doi:10.1186/s13229-015-0004-5

31. Gockley J, Willsey AJ, Dong S, Dougherty JD, Constantino JN, Sanders SJ. The female protective effect in autism spectrum disorder is not mediated by a single genetic locus. Mol Autism. 2015. doi:10.1186/s13229-015-0014-3 
32. Nordahl CW, losif AM, Young GS, Perry LM, Dougherty R, Lee A et al. Sex differences in the corpus callosum in preschool-aged children with autism spectrum disorder. Mol Autism. 2015. doi:10.1186/s13229-015-0005-4

33. Mandy W, Tchanturia K. Do women with eating disorders who have social and flexibility difficulties really have autism? A case series. Mol Autism. 2015. doi:10.1186/2040-2392-6-6

34. Koch SV, Larsen JT, Mouridsen SE, Bentz M, Petersen L, Bulik C et al. Autism spectrum disorder in individuals with anorexia nervosa and in their first- and second-degree relatives: Danish nationwide register-based cohort-study. Br J Psychiatry. 2015. doi:10.1192/bjp.bp.114.153221

35. Trubanova A, Donlon K, Kreiser NL, Ollendick TH, White SW. Underidentification of ASD in females: a case series illustrating the unique presentation of ASD in young adult females. Scandinavian J Child Adol Psychiatry Psychol. 2014;2(2):66-76.

36. Luciano CC, Keller R, Politi P, Aguglia E, Magnano F, Burti L, et al. Misdiagnosis of high function autism spectrum disorders in adults: an Italian case series. Autism Open Access. 2014;4(131):2. doi:10.4172/ 2165-7890.1000131.

37. Aggarwal S, Angus B. Misdiagnosis versus missed diagnosis: diagnosing autism spectrum disorder in adolescents. Australas Psychiatry. 2015. doi:10.1177/1039856214568214

38. Begeer S, Mandell D, Wijnker-Holmes B, Venderbosch S, Rem D, Stekelenburg F, et al. Sex differences in the timing of identification among children and adults with autism spectrum disorders. J Autism Dev Disord. 2013;43(5):1151-6. doi:10.1007/s10803-012-1656-z

39. Giarelli E, Wiggins LD, Rice CE, Levy SE, Kirby RS, Pinto Martin J, et al. Sex differences in the evaluation and diagnosis of autism spectrum disorders among children. Disabil Health J. 2010;3(2):107-16. doi:10.1016/ j.dhjo.2009.07.001.

40. Shattuck PT, Durkin M, Maenner M, Newschaffer C, Mandell DS, Wiggins L, et al. Timing of identification among children with an autism spectrum disorder: findings from a population-based surveillance study. J Am Acad Child Adolesc Psychiatry. 2009;48(5):474-83. doi:10.1097/ CHI.0b013e31819b3848.

41. Dworzynski K, Ronald A, Bolton P, Happé F. How different are girls and boys above and below the diagnostic threshold for autism spectrum disorders? J Am Acad Child Adolesc Psychiatry. 2012;51(8):788-97. doi:10.1016/ j.jaac.2012.05.018

42. Russell G, Steer C, Golding J. Social and demographic factors that influence the diagnosis of autistic spectrum disorders. Soc Psychiatry Psychiatr Epidemiol. 2011;46(12):1283-93. doi:10.1007/s00127-010-0294-Z.

43. Hofvander B, Delorme R, Chaste P, Nyden A, Wentz E, Stahlberg O et al. Psychiatric and psychosocial problems in adults with normal-intelligence autism spectrum disorders. BMC Psychiatry. 2009;9:35. doi:10.1186/1471244X-9-35.

44. Lugnegård T, Hallerback MU, Gillberg C. Psychiatric comorbidity in young adults with a clinical diagnosis of Asperger syndrome. Res Dev Disabil. 2011;32(5):1910-7. doi:10.1016/j.ridd.2011.03.025.

45. Kirkovski M, Enticott PG, Fitzgerald PB. A review of the role of female gender in autism spectrum disorders. J Autism Dev Disord. 2013:43(11):2584-603. doi:10.1007/s10803-013-1811-1.

46. Surén P, Stoltenberg C, Bresnahan M, Hirtz D, Lie KK, Lipkin WI, et al. Early growth patterns in children with autism. Epidemiology. 2013;24(5):660-70. doi:10.1097/EDE.0b013e31829e1d45

47. Nordahl CW, Lange N, Li DD, Barnett LA, Lee A, Buonocore MH, et al. Brain enlargement is associated with regression in preschool-age boys with autism spectrum disorders. Proc Natl Acad Sci U S A. 2011;108(50):20195-200. doi:10.1073/pnas.1107560108.

48. Campbell DJ, Chang J, Chawarska K. Early generalized overgrowth in autism spectrum disorder: prevalence rates, gender effects, and clinical outcomes. J Am Acad Child Adolesc Psychiatry. 2014;53(10):1063-73. doi:10.1016/ j.jaac.2014.07.008.

49. Baron-Cohen S, Auyeung B, Norgaard-Pedersen B, Hougaard DM, Abdallah MW, Melgaard L, et al. Elevated fetal steroidogenic activity in autism. Mol Psychiatry. 2015;20(3):369-76. doi:10.1038/mp.2014.48.

50. Zerbo O, Yoshida C, Grether JK, Van de Water J, Ashwood P, Delorenze GN, et al. Neonatal cytokines and Chemokines and risk of autism spectrum disorder: the early markers for autism (EMA) study: a case - control study. J Neuroinflammation. 2014;11:113. doi:10.1186/1742-2094-11-113.
51. Robinson EB, Lichtenstein P, Anckarsater H, Happe F, Ronald A. Examining and interpreting the female protective effect against autistic behavior. Proc Natl Acad Sci U S A. 2013;110(13):5258-62. doi:10.1073/pnas.1211070110.

52. Grønborg TK, Schendel DE, Parner ET. Recurrence of autism spectrum disorders in full- and half-siblings and trends over time: a population-based cohort study. JAMA Pediatrics. 2013;167(10):947-53. doi:10.1001/ jamapediatrics.2013.2259.

53. Sandin S, Lichtenstein P, Kuja-Halkola R, Larsson H, Hultman CM, Reichenberg A. The familial risk of autism. JAMA. 2014;311(17):1770-7. doi:10.1001/jama.2014.4144.

54. Zhao X, Leotta A, Kustanovich V, Lajonchere C, Geschwind DH, Law K, et al. A unified genetic theory for sporadic and inherited autism. Proc Natl Acad Sci U S A. 2007;104(31):12831-6. doi:10.1073/pnas.0705803104.

55. Idring S, Rai D, Dal H, Dalman C, Sturm H, Zander E, et al. Autism spectrum disorders in the stockholm youth cohort: design, prevalence and validity. PLoS One. 2012;7(7), e41280. doi:10.1371/journal.pone.0041280.

56. Mattila ML, Kielinen M, Linna SL, Jussila K, Ebeling H, Bloigu R, et al. Autism spectrum disorders according to DSM-IV-TR and comparison with DSM-5 draft criteria: an epidemiological study. J Am Acad Child Adolesc Psychiatry. 2011;50(6):583-92. e11. doi:10.1016/j.jaac.2011.04.001.

57. Turner TN, Sharma K, Oh EC, Liu YP, Collins RL, Sosa MX, et al. Loss of deltacatenin function in severe autism. Nature. 2015;520(7545):51-6. doi:10.1038/ nature14186.

58. Hallmayer J, Cleveland S, Torres A, Phillips J, Cohen B, Torigoe T, et al. Genetic heritability and shared environmental factors among twin pairs with autism. Arch Gen Psychiatry. 2011;68(11):1095-102. doi:10.1001/ archgenpsychiatry.2011.76.

59. Gaugler T, Klei L, Sanders SJ, Bodea CA, Goldberg AP, Lee AB, et al. Most genetic risk for autism resides with common variation. Nat Genet. 2014;46(8):881-5. doi:10.1038/ng.3039.

60. Colvert E, Tick B, McEwen F, Stewart C, Curran SR, Woodhouse E et al. Heritability of Autism Spectrum Disorder in a UK population-based twin sample. JAMA Psychiatry. 2015. doi:10.1001/jamapsychiatry.2014.3028

61. Kim YS, Leventhal BL. Genetic epidemiology and insights into interactive genetic and environmental effects in autism spectrum disorders. Biol Psychiatry. 2015;77(1):66-74. doi:10.1016/j.biopsych.2014.11.001.

62. Sarachana T, Xu M, Wu RC, Hu WW. Sex hormones in autism: androgens and estrogens differentially and reciprocally regulate RORA, a novel candidate gene for autism. PLoS One. 2011;6(2):e17116. doi:10.1371/ journal.pone.0017116.

\section{Submit your next manuscript to BioMed Central and take full advantage of:}

- Convenient online submission

- Thorough peer review

- No space constraints or color figure charges

- Immediate publication on acceptance

- Inclusion in PubMed, CAS, Scopus and Google Scholar

- Research which is freely available for redistribution 